\title{
APLICAÇÃO TARDIA DE NITROGÊNIO NO FEIJOEIRO EM SISTEMA DE PLANTIO DIRETO ${ }^{(1)}$
}

\author{
ROGÉRIO PERES SORATTO ${ }^{(2)}$; CARLOS ALEXANDRE COSTA CRUSCIOL ${ }^{(3,5)}$; \\ LAERTE MARQUES DA SILVA $^{(4)}$; LEANDRO BORGES LEMOS $^{(3)}$
}

\begin{abstract}
RESUMO
A adoção de técnicas que possibilitem a maximização da eficiência do uso de nitrogênio pelo feijoeiro é de extrema importância para aumentar a produtividade e qualidade de grãos, reduzir o custo de produção e evitar contaminação ambiental. O objetivo deste trabalho foi avaliar a resposta do feijoeiro (Phaseolus vulgaris L.) à aplicação de nitrogênio em cobertura nos estádios $\mathrm{V}_{4} \mathrm{e}$ no início do $\mathrm{R}_{7}$, em sistema de plantio direto. O delineamento experimental foi em blocos ao acaso, em esquema fatorial $2 \times 4$, com quatro repetições. Os tratamentos foram constituídos pela aplicação de dois níveis de $\mathrm{N}(0$ e $90 \mathrm{~kg}$ ha-1) no estádio $\mathrm{V}_{4}$, combinados com quatro níveis de $\mathrm{N}\left(0,30,60\right.$ e $\left.120 \mathrm{~kg} \mathrm{ha}^{-1}\right)$ no início do estádio $\mathrm{R}_{7}$ Quando não foi realizada adubação nitrogenada de cobertura no estádio $\mathrm{V}_{4}$, a aplicação de $\mathrm{N}$ no início do estádio $R_{7}$ aumentou a produtividade de grãos do feijoeiro em sistema de plantio direto. A produtividade máxima de grãos foi obtida com a aplicação exclusiva de $90 \mathrm{~kg} \mathrm{ha}^{-1}$ de $\mathrm{N}$ no estádio $\mathrm{V}_{4}$, sendo necessárias, para atingir o mesmo nível de produtividade, maiores doses de $\mathrm{N}$ quando aplicadas apenas em $R_{7}$. Quando é realizada aplicação de $\mathrm{N}$ em $V_{4}$, adubações adicionais em $R_{7}$ não resultam em aumento de produtividade. A aplicação de $\mathrm{N}$ em cobertura no estádio $\mathrm{V}_{4}$ foi mais eficiente do que a aplicação em $R_{7}$, acarretando em maior incremento na produtividade por unidade do nutriente aplicado. A aplicação de $\mathrm{N}$ em cobertura, nos estádios $V_{4}$ e início do $R_{7}$, proporcionou aumento no teor de proteína nos grãos do feijoeiro.
\end{abstract}

Palavras-chave: Phaseolus vulgaris, adubação nitrogenada, época de aplicação, proteína.

\section{ABSTRACT \\ LATE NITROGEN APPLICATION ON COMMON BEAN IN NO-TILLAGE SYSTEM}

The utilization of techniques that allow the maximization efficiency of nitrogen use by the common bean is important to increase grain yield and quality, to decrease production cost, and to avoid environmental contamination. The objective of this work was to evaluate the performance of common bean (Phaseolus vulgaris L.) in response to levels of sidedressed nitrogen applied on the $\mathrm{V}_{4}$ and on the beginning of $R_{7}$ development stages, in no-tillage system. A randomized complete block design, in a $2 x$ 4 factorial scheme, with four replications was used. The treatments were a combination of two $\mathrm{N}$ levels $\left(0\right.$ and $\left.90 \mathrm{~kg} \mathrm{ha}^{-1}\right)$ in the $\mathrm{V}_{4}$ stage and four $\mathrm{N}$ levels $\left(0,30,60\right.$, and $120 \mathrm{~kg} \mathrm{ha}^{-1}$ ) in the beginning of the $R_{7}$ stage. When nitrogen fertilization was not used in $V_{4}$ stage, the application in the beginning of $R_{7}$ stage increased the common bean grain yield in no-tillage system. Nitrogen application in the $\mathrm{V}_{4}$ stage $(90 \mathrm{~kg}$

$\left({ }^{1}\right)$ Recebido para publicação em 24 de setembro de 2004 e aceito em 10 de janeiro de 2005.

$\left(^{2}\right)$ Universidade Estadual de Mato Grosso do Sul - Unidade Universitária de Cassilândia, Rod. MS 306 km 6,4, 79540-000 Cassilândia (MS). E-mail: soratto@uems.br

$\left({ }^{3}\right)$ Departamento de Produção Vegetal - FCA - UNESP- Fazenda Experimental Lageado, Caixa Postal 237, 18603-970 Botucatu (SP), Brasil. E-mail: crusciol@fca.unesp.br; leandrobl@fca.unesp.br

$\left(^{4}\right)$ Doutorando em Agronomia (Agricultura), Faculdade de Ciências Agronômicas (FCA) - UNESP - Fazenda Experimental Lageado, Botucatu (SP). E-mail: laertemarques@fca.unesp.br

$\left({ }^{5}\right)$ Com bolsa de produtividade do CNPq. 
$\mathrm{ha}^{-1}$ ) provided the maximum grain yield. When nitrogen was applied in the $V_{7}$ stage, its was necessary greater levels for obtaining the same yield. When nitrogen fertilization was used in the $V_{4}$ stage, the application in the beginning of the $R_{7}$ stage did not increase common bean grain yield. Nitrogen side dressing in the $V_{4}$ stage was more efficient than in $V_{7}$, resulting in higher grain yield per nutrient unit. The application of nitrogen in the $V_{4}$ stage and in the beginning of $R_{7}$ development stage, increased grain protein content.

Key words: Phaseolus vulgaris, nitrogen fertilization, time of application, protein.

\section{INTRODUÇÃO}

O cultivo do feijoeiro em sistema de plantio direto tem aumentado no Brasil, devido a inúmeros benefícios que esse sistema proporciona às características físicas, químicas e biológicas do solo. O sistema de plantio direto, em razão da manutenção dos resíduos vegetais na sua superfície, promove maior proteção contra o impacto direto das gotas de chuva, favorece a infiltração, reduz perda de água por escoamento superficial e perda de solo por erosão (Hermani et al., 1999, Stone e Silveira, 1999). Nesse sistema, porém, pelo fato de os restos culturais permanecerem na superfície do solo, a taxa de mineralização da matéria orgânica é mais lenta, quando comparada com sistema convencional (Gonçalves e Ceretta, 1999), o que tem acarretado menor disponibilidade de nitrogênio às plantas, principalmente, na fase de implantação até a estabilização do sistema (SorATto et al., 2001; Silva et al., 2002; SorAtTo et al., 2004). Dessa forma, a dose de nitrogênio na adubação do feijoeiro pode estar condicionada ao tipo de resíduo vegetal (gramínea ou leguminosa) presente na superfície do solo, já que palhada com elevada relação $C / N$, característica da maioria das gramíneas, proporciona maior imobilização de nitrogênio para sua decomposição (CERetta et al., 2002), sendo necessário maior quantidade desse nutriente para obtenção de produtividades elevadas (BORDIN, et al., 2003; SORATTO et al., 2004).

O feijoeiro é planta exigente e, por ser de ciclo curto, necessita que os nutrientes estejam prontamente disponíveis nos estádios de demanda, para que não haja limitação da produtividade (SILva e SILveIRA, 2000). O N é o nutriente absorvido em maiores quantidades pelo feijoeiro e, pelo fato de aproximadamente $50 \%$ do $\mathrm{N}$ total absorvido ser exportado para os grãos, a sua deficiência é a mais freqüente (OliveIRA et al., 1996). Esse nutriente tem grande importância, principalmente nas fases de florescimento e enchimentos de grãos, pois, como há vagens e grãos crescendo quase ao mesmo tempo, a demanda por N nessa fase é alta (Portes, 1996). Dessa forma, o feijoeiro não absorve todo o $\mathrm{N}$ que necessita nos primeiros 50 dias do ciclo (Rosolem, 1987). WESTERMANN et al. (1981) observaram uma absorção de até $3,5 \mathrm{~kg} /$ ha dia ${ }^{-1}$ no período de enchimento de grãos.
De acordo com Hungria et al. (1985), 60\% do N mineral total acumulado pelo feijoeiro durante o ciclo, são absorvidos entre os estádios de florescimento e meados do estádio de enchimento dos grãos. Como o nitrogênio das folhas é translocado para os grãos, as folhas mais velhas cairão e a taxa fotossintética das folhas remanescentes decrescerá quase simultaneamente se a disponibilidade do nutriente no solo for baixa nessa fase do ciclo da cultura (PORTES, 1996), podendo ocorrer redução da produtividade de grãos. Além disso, como o $\mathrm{N}$ é um nutriente que se perde facilmente por lixiviação, volatilização e desnitrificação no sistema solo-planta, o seu manejo adequado é tido como um dos mais difíceis (SANTOS, et al., 2003), sendo essencial, para a obtenção de altas produtividades, que esse nutriente seja colocado à disposição da planta em tempo e locais adequados (CARvalho, et al., 2001). Dessa forma, técnicas de manejo que possibilitem a maximização de absorção de $\mathrm{N}$ pelo feijoeiro são de extrema importância, devido ao alto custo dos fertilizantes nitrogenados e as perdas de $\mathrm{N}$ por lixiviação, que podem representar riscos ao ambiente pela contaminação de mananciais de água (SANTOS et al., 2003).

Para Rosolem (1996), a adubação nitrogenada deve ser realizada de modo que propicie boa nutrição da planta na época em que ainda é possível aumentar o número de vagens por planta, ou seja, até o início do florescimento. MiYASAKA et al. (1963) recomendam aplicação do $\mathrm{N}$ em cobertura até 20 dias após a emergência das plântulas (DAE). Em outros trabalhos, observa-se que a adubação nitrogenada de cobertura pode ser realizada no máximo até 36 DAE (Rosolem, 1987). Contudo, SorATTo et al. (2001) verificaram que em feijoeiro cultivado em sistema de plantio direto, após a cultura do milho, a aplicação do nitrogênio em cobertura aos 15 DAE, proporcionou maior produtividade de grãos, quando comparado com a aplicação aos 35 DAE.

Outro fator importante é que, no Brasil, a cultura do feijoeiro ocupa posição de destaque, não apenas pelo volume de grãos produzidos, mas também pela importância dessa leguminosa na alimentação humana. O feijão é a principal fonte de proteína da maioria da população brasileira, o que tem proporcionado interesse no estudo de técnicas que acarretem aumento da produtividade e da qualidade dos grãos. 
O objetivo deste trabalho foi avaliar a resposta do feijoeiro à aplicação de nitrogênio em cobertura nos estádios de $3 .^{a}$ folha trifoliolada e no início da formação das vagens em sistema de plantio direto.

\section{MATERIAL E MÉTODOS}

O trabalho foi realizado na Fazenda Experimental Lageado pertencente à Faculdade de Ciências Agronômicas - UNESP, município de Botucatu, SP ( $48^{\circ} 23^{\prime} \mathrm{W}$ e $22^{\circ} 58^{\prime} \mathrm{S}$; $765 \mathrm{~m}$ de altitude). O solo do local é Nitossolo Vermelho estruturado (EMBrapa, 1999). O clima, conforme a classificação de Köppen, é do tipo Cwa, que se caracteriza como tropical de altitude, com inverno seco e verão quente e chuvoso. Durante a realização do experimento ocorreram $596 \mathrm{~mm}$ de chuvas, bem distribuídas durante o período de cultivo.

Antes da instalação do experimento, foi coletada amostra composta de 10 subamostras, na camada de 0-0,20 m, para a determinação das características químicas do solo, realizadas de acordo com Raij e Quaggio (1983), cujos resultados foram: matéria orgânica, $26,0 \mathrm{~g} \mathrm{dm}^{-3} ; \mathrm{pH}\left(\mathrm{CaCl}_{2}\right), 4,4 ; \mathrm{P}$ (resina), $14,9 \mathrm{mg} \mathrm{dm}^{-3}$; K, Ca e $\mathrm{Mg}, 1,6,41,3$ e 20,6 $\mathrm{mmol}_{\mathrm{c}} \mathrm{dm}^{-3}$, respectivamente, e saturação por bases, $56 \%$.

O delineamento experimental utilizado foi o de blocos ao acaso, em esquema fatorial $2 \times 4$, com quatro repetições. Os tratamentos foram constituídos pela aplicação de dois níveis de $\mathrm{N}\left(0\right.$ e $\left.90 \mathrm{~kg} \mathrm{ha}^{-1}\right)$ no estádio $\mathrm{V}_{4}$ (FERnANDEZ et al, 1986), ou seja, 22 DAE e quatro níveis de $\mathrm{N}\left(0,30,60\right.$ e $\left.120 \mathrm{~kg} \mathrm{ha}^{-1}\right)$, no início do estádio $R_{7}$ (50 DAE), aplicados em cobertura, tendo como fonte o nitrato de amônio. Cada parcela foi constituída por seis linhas de $5 \mathrm{~m}$ de comprimento. A área útil foi constituída pelas quatro linhas centrais, desprezando-se 0,50 $\mathrm{m}$ em ambas as extremidades de cada linha.

O experimento foi instalado em área cultivada há três anos no sistema de plantio direto, com a sucessão milheto/milho, milheto/arroz e aveia-preta/ arroz/aveia-preta, o que a caracterizava como de alta resposta à aplicação de $\mathrm{N}$ para o feijoeiro (AMBROSANO et al., 1996). No momento da instalação do experimento a área encontrava-se coberta com palhada de aveia-preta. A dessecação da cobertura vegetal do solo foi realizada mediante a aplicação de $1,6 \mathrm{~kg} \mathrm{ha}^{-1}$ do i.a. de glifosate. A semeadura foi realizada mecanicamente em $7 / 1 / 2004$, utilizando a cultivar Pérola com espaçamento de $0,45 \mathrm{~m}$ entre as linhas e 15 sementes por metro linear. Por ocasião da semeadura, aplicaram-se em todos os tratamentos, 230 $\mathrm{kg} \mathrm{ha}^{-1} \mathrm{da}$ fórmula 08-28-16 de NPK. A emergência das plântulas ocorreu em 12/1/2004. O florescimento pleno da cultura ocorreu aos 41 DAE e o ciclo teve a duração de 86 dias em todos os tratamentos.

Nas adubações de cobertura o adubo foi distribuído sobre a superfície do solo, ao lado e aproximadamente a $10 \mathrm{~cm}$ das fileiras de plantas.

O controle das plantas daninhas foi realizado mediante duas aplicações seqüenciais do herbicida fluazifop-p-butil + fomesafen $\left(100+125\right.$ g i.a. ha ${ }^{-1}$ de em cada aplicação). Durante o desenvolvimento da cultura foram realizados os tratos culturais fitossanitários.

Por ocasião do florescimento pleno determinou-se massa de matéria seca da parte aérea das plantas, coletando-se 10 plantas por parcela e secando-as em estufa com circulação forçada de ar a 60-70 ${ }^{\circ} \mathrm{C}$, até atingir massa constante. Para determinar o teor de $\mathrm{N}$ total nas folhas foram coletadas todas as folhas de 10 plantas de cada parcela no florescimento pleno e secas em estufa com circulação forçada de ar a $60-70{ }^{\circ} \mathrm{C}$, até atingir massa constante, e em seguida foram moídas e submetidas à análise, conforme método descrito em Malavolta et al. (1997). Por ocasião da colheita foram coletadas 10 plantas de cada parcela e determinados o número de vagens / planta, o número de grãos/vagem e a massa de cem grãos. Em duas fileiras da área útil de cada parcela, as plantas foram arrancadas e deixadas a secar em pleno sol e em seguida submetidas à trilha mecânica; a umidade dos grãos foi corrigida para $0,13 \mathrm{~kg} \mathrm{~kg}^{-1}$ (base úmida), obtendo-se a produtividade de grãos. Para determinar o teor de proteína, os grãos foram secos em estufa com circulação forçada de ar a 60-70 ${ }^{\circ} \mathrm{C}$, até atingir massa constante; em seguida, foram moídos e submetidos à análise para determinação do teor de $\mathrm{N}$, conforme método descrito em Malavolta et al. (1997), posteriormente, multiplicando-se o teor de $\mathrm{N}$ pelo fator 6,25 , obteve-se o teor de proteína nos grãos. Com a multiplicação do valor do teor de proteína pelo valor de produtividade de grãos da parcela correspondente, obteve-se a produtividade de proteína.

Os resultados foram submetidos à análise de variância. As médias referentes à aplicação de $\mathrm{N}$ no estádio $\mathrm{V}_{4}$ foram comparadas pelo teste DMS a 5\% de probabilidade, enquanto os efeitos dos níveis de $\mathrm{N}$ aplicados no início do estádio $R_{7}$ foram avaliados por meio de análise de regressão, adotando-se como critério para escolha do modelo a magnitude dos coeficientes de regressão significativos a $5 \%$ de probabilidade pelo teste t. Determinou-se também o fator de utilização do $\mathrm{N}$ aplicado, mediante a relação $\mathrm{kg} \mathrm{ha}^{-1}$ de $\mathrm{N}$ aplicado / $\mathrm{kg} \mathrm{ha}^{-1}$ da produtividade incrementada, em relação à testemunha (sem aplicação de N), em ambas as épocas de aplicação de $\mathrm{N}$. 


\section{RESULTADOS E DISCUSSÃO}

Nos tratamentos que receberam $90 \mathrm{~kg} \mathrm{ha}^{-1} \mathrm{de}$ $\mathrm{N}$ no estádio $\mathrm{V}_{4}$ ocorreu maior massa de matéria seca (Tabela 1). Os resultados podem ser explicados pela maior demanda de nitrogênio, já que os resíduos culturais presentes na área, por serem provenientes de gramíneas, provavelmente possuíam alta relação $\mathrm{C} / \mathrm{N}$, o que pode ter aumentado a intensidade de imobilização de $\mathrm{N}$ pelos microrganismos, proporcionando menor disponibilidade do nutriente às plantas, na fase inicial do desenvolvimento, corroborando com CERETTA et al. (2002). Além disso, no sistema de plantio direto, devido à permanência dos restos culturais na superfície do solo, a taxa de mineralização da matéria orgânica é lenta (GoNÇALVES e CERETTA, 1999), o que promove reduzida liberação de $\mathrm{N}$ para a cultura subseqüente, na fase inicial do desenvolvimento. SoratTo et al. (2001) e PIASKOWSKI et al. (2001) também verificaram aumento da massa de matéria seca do feijoeiro cultivado em sucessão a gramíneas, em plantio direto, em virtude da aplicação de $\mathrm{N}$ em cobertura. SoratTo et al. (2001) verificaram que a aplicação de todo o $\mathrm{N}$ aos $15 \mathrm{DAE}$ proporcionou maior acúmulo de matéria seca nas plantas, quando comparada com a aplicação aos 25 ou 35 DAE. Os resultados evidenciam que, embora a época de máxima absorção de $\mathrm{N}$ situa-se entre os estádios de florescimento e meados do enchimento de grãos, o feijoeiro necessita de $\mathrm{N}$ para seu crescimento inicial (Ambrosano et al., 1996; Carvalho et al., 2001), principalmente, quando cultivado em sistema de plantio direto, em sucessão a gramíneas.

Tabela 1. Matéria seca da parte aérea, teor de $\mathrm{N}$ nas folhas, componentes da produção, produtividade de grãos, teor de proteína nos grãos e produtividade de proteína bruta do feijoeiro cultivado em sistema de plantio direto, em vista da aplicação de nitrogênio em cobertura no estádio $\mathrm{V}_{4}(22 \mathrm{DAE}){ }^{(1)}$

\begin{tabular}{|c|c|c|c|}
\hline \multirow{2}{*}{ Variável analisada } & \multicolumn{2}{|c|}{$\mathrm{N}$ em cobertura no estádio $V_{4}$} & \multirow{2}{*}{$\mathrm{CV}$} \\
\hline & 0 & 90 & \\
\hline & - & & $\%$ \\
\hline Matéria seca $\left(\text { g planta }^{-1}\right)^{(2)}$ & $7,9 \mathrm{~b}$ & $10,2 a$ & 22,9 \\
\hline Teor de $\mathrm{N}$ nas folhas $\left(\mathrm{g} \mathrm{kg}^{-1}\right)^{(2)}$ & $37,5 b$ & $42,4 \mathrm{a}$ & 8,3 \\
\hline Número de vagens por planta & $6,6 b$ & $7,7 \mathrm{a}$ & 16,0 \\
\hline Número de grãos por vagem & 4,5 & 4,4 & 10,4 \\
\hline Massa de 100 grãos (g) & 27,7 & 28,1 & 5,2 \\
\hline Produtividade de grãos $\left(\mathrm{kg} \mathrm{ha}^{-1}\right)$ & $2.653 b$ & $3.137 \mathrm{a}$ & 13,4 \\
\hline Teor de proteína nos grãos $\left(\mathrm{g} \mathrm{kg}^{-1}\right)$ & $198,2 b$ & $213,5 a$ & 6,8 \\
\hline Produtividade de proteína $\left(\mathrm{kg} \mathrm{ha}^{-1}\right)$ & $528,5 b$ & $668,3 a$ & 14,4 \\
\hline
\end{tabular}

$\left({ }^{1}\right)$ Para cada variável, médias seguidas de letras distintas na linha, diferem entre si pelo teste DMS a 5\% de probabilidade.

$\left({ }^{2}\right)$ Medidas feitas no florescimento (estádio $R_{6}$ ). As demais foram realizadas na colheita

A aplicação de $\mathrm{N}$ no estádio $\mathrm{V}_{4}$ proporcionou maior teor do nutriente nas folhas do feijoeiro (Tabela 1). Mesmo nos tratamentos que não receberam $N$ no estádio $\mathrm{V}_{4}$, os teores de $\mathrm{N}$ nas folhas estavam dentro da faixa considerada adequada para o feijoeiro, ou seja, 30-50 $\mathrm{g} \mathrm{kg}^{-1}$ (AмBrosAno et al., 1997). SorAtTo et al. (2004) verificaram que a elevação no teor de $\mathrm{N}$ nas folhas do feijoeiro, mesmo dentro da faixa considerada adequada, promoveu acréscimos no teor de clorofila e, conseqüentemente, na produtividade de grãos. Segundo esses autores, em sistema de plantio direto, houve maior aproveitamento do $\mathrm{N}$ pelo feijoeiro, provavelmente, devido à manutenção de maior umidade no solo.

O número de vagens por planta foi influenciado pela interação entre aplicação de $\mathrm{N}$ no estádio $\mathrm{V}_{4}$ e no início do $\mathrm{R}_{7}$ (Figura 1 ). Com a aplicação de $\mathrm{N}$ no estádio $\mathrm{V}_{4}$, observou-se maior número de vagens por planta. Essa é uma característica resultante da adubação nitrogenada, pois, quando a planta é mal nutrida em relação a esse nutriente, produz menos flores e, conseqüentemente, menos vagens (Portes, 1996). Dessa forma, pelos resultados, verifica-se a necessidade da utilização de doses elevadas de $\mathrm{N}$ no estádio inicial do desenvolvimento de feijoeiro em sistema de plantio direto. Verificou-se também que, tanto sem aplicação quanto com a aplicação de $90 \mathrm{~kg} \mathrm{ha}^{-1}$ de $\mathrm{N}$ no estádio $\mathrm{V}_{4}$, o emprego de níveis crescentes do nutriente no estádio $R_{7}$ proporcionou aumento do número de vagens por planta (Figura 1). No entanto, nos tratamentos que receberam $\mathrm{N}$ no estádio $\mathrm{V}_{4}$, a aplicação do nutriente no início do estádio $R_{7}$ 
proporcionou incremento linear nessa característica, enquanto nos tratamentos que não receberam $\mathrm{N}$ no estádio $\mathrm{V}_{4}$ houve efeito quadrático da aplicação do elemento no estádio $R_{7}$. Assim, nota-se que em plantas bem nutridas e com maior massa de matéria seca, a aplicação de até $120 \mathrm{~kg} \mathrm{ha}^{-1}$ de $\mathrm{N}$, após o início da formação das vagens, pode promover maior fixação de flores e vagens. Nos tratamento que não receberam $\mathrm{N}$ no estádio $\mathrm{V}_{4}$, porém, o maior número de vagens por planta foi alcançado com a dose máxima estimada de $72 \mathrm{~kg} \mathrm{ha}^{-1}$ de $\mathrm{N}$ aplicado no início do estádio $\mathrm{R}_{7}$.
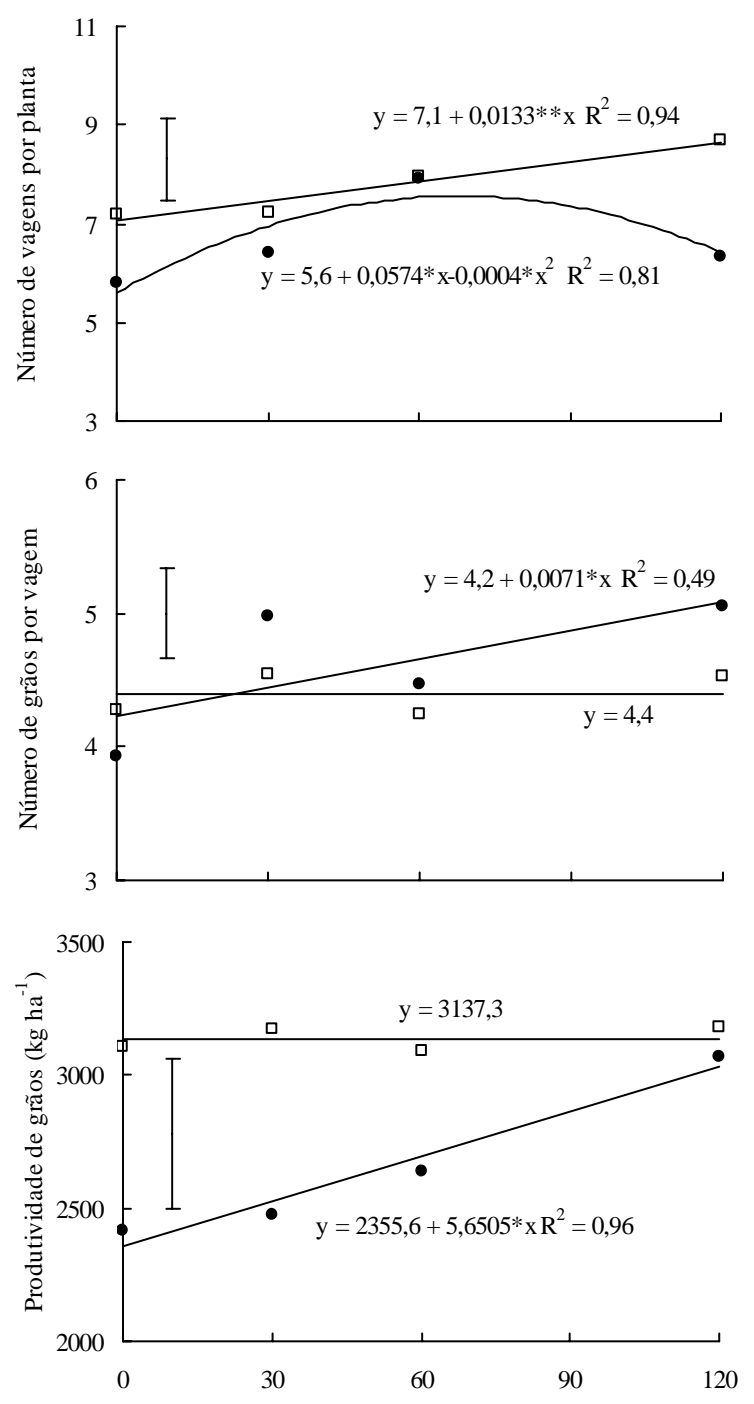

$\mathrm{N}$ em cobertura no início do estádio $\mathrm{R}_{7}\left(\mathrm{~kg} \mathrm{ha}^{-1}\right)$

Figura 1. Número de vagens por planta, número de grãos por vagem e produtividade de grãos do feijoeiro em sistema de plantio direto em função da aplicação de níveis de $\mathrm{N}$ em cobertura no início do estádio R7 (50 DAE), sem $(\bullet)$ e com $(\square)$ aplicação de $90 \mathrm{~kg} \mathrm{ha}^{-1}$ de N em cobertura no estádio V4 $(22 \mathrm{DAE}) .{ }^{*} \mathrm{e}^{* *}$ Significativo a $5 \%$ e $1 \%$ de probabilidade pelo teste $t$, respectivamente. Barras verticais indicam o valor de DMS a $5 \%$ de probabilidade.
O número de grãos por vagem é uma característica de alta herdabilidade genética, que sofre pouca influência do ambiente (ANDRADE et al., 1998). No entanto, esse componente da produção foi incrementado pela aplicação de $\mathrm{N}$ no início do estádio $R_{7}$, nas parcelas que não receberam o elemento no estádio $V_{4}$ (Figura 1). Silva et al. (1989), SAntos et al. (2003) e SoRATto et al. (2004) também verificaram aumento do número de grãos por vagem do feijoeiro com a aplicação de $\mathrm{N}$ em cobertura. A massa de cem grãos não foi afetada pelos tratamentos. Segundo Silva e Silveira (2000) e Soratto et al. (2004), doses de $\mathrm{N}$ não causam grande variação na massa de cem grãos. Esses resultados confirmam o princípio de que essa é uma das características que apresenta pequena variação, em função das alterações no meio de cultivo. Assim, em condições adversas, com restrição de N, a planta de feijão preferencialmente formará poucos grãos nas vagens fixadas ao invés de vários e mal formados.

Quanto à produtividade de grãos, houve efeito da interação entre aplicação de $\mathrm{N}$ no estádio $\mathrm{V}_{4}$ e no início do $R_{7}$. A aplicação de $\mathrm{N}$ no início do estádio $R_{7}$ proporcionou aumento linear na produtividade de grãos nas plantas que não receberam $\mathrm{N}$ no estádio $\mathrm{V}_{4}$, porém não se observou efeito sobre a produtividade das plantas que receberam $90 \mathrm{~kg} \mathrm{ha}^{-1}$ de $\mathrm{N}$ no estádio $\mathrm{V}_{4}$ (Figura 1). Pelos resultados, apesar de promover aumento de produtividade das plantas que não receberam $\mathrm{N}$ no estádio $\mathrm{V}_{4}$, foi necessária a aplicação de $120 \mathrm{~kg} \mathrm{ha}^{-1}$ de $\mathrm{N}$ no início do estádio $\mathrm{R}_{7}$ para proporcionar o mesmo nível de produtividade obtido com a aplicação de $90 \mathrm{~kg} \mathrm{ha}^{-1}$ de $\mathrm{N}$ no estádio $\mathrm{V}_{4}$. A aplicação de $90 \mathrm{~kg} \mathrm{ha}^{-1}$ de $\mathrm{N}$ no estádio $\mathrm{V}_{4}$ proporcionou um aumento de $28 \%$ na produtividade de grãos, enquanto a aplicação no início de $R_{7}$, resultou em apenas $18 \%$. Verificou-se, dessa forma, menor eficiência da adubação nitrogenada quando aplicada no início do estádio $R_{7}$, ou seja, a aplicação nesse estádio aumentou o fator de utilização do $\mathrm{N}$, em comparação com a aplicação no estádio $\mathrm{V}_{4}$ (Tabela 2). Assim, apesar de maior demanda do feijoeiro por $\mathrm{N}$ ocorrer entre os estádios de florescimento e meados do enchimento dos grãos (Hungria et al., 1985), notouse, pelos resultados, a importância da aplicação de $\mathrm{N}$ na fase vegetativa, ou seja, em época que promova crescimento da planta, pois, plantas mais robustas, com mais ramificações e que produzam maior número de estruturas reprodutivas, acarretam maior produtividade de grãos, como também foi verificado por Carvalho et al. (2001) e Soratto et al. (2004). Soratto et al. (2001) e SiLva et al. (2002) verificaram que $\mathrm{o}$ atraso no fornecimento de $\mathrm{N}$ à planta (aplicação de todo o $\mathrm{N}$ aos $35 \mathrm{DAE}$ ), refletiu em baixa produtividade do feijoeiro em plantio direto sobre palhada de milho, provavelmente em vista da alta imobilização biológica do $\mathrm{N}$ do solo. 
Tabela 2. Aumento da produtividade de grãos de feijoeiro e fator de utilização do nitrogênio, considerando a aplicação de 90 kg ha ${ }^{-1}$ de $\mathrm{N}$ em cobertura no estádio $\mathrm{V}_{4}$ ou no início do estádio $\mathrm{R}_{7}$, em sistema de plantio direto

\begin{tabular}{lcr}
\hline Variável & \multicolumn{2}{c}{ Época de aplicação do N em cobertura } \\
\cline { 2 - 3 } & Estádio $\mathrm{V}_{4}$ & Início do estádio $\mathrm{R}_{7}$ \\
\hline Aumento da produtividade $\left(\mathrm{kg} \mathrm{ha}^{-1}\right)^{(1)}$ & 686 & 445 \\
Fator $\mathrm{N}^{(2)}$ & 0,131 & $0,202{ }^{(3)}$ \\
\hline
\end{tabular}

$\left({ }^{1}\right)$ Obtido em relação à média de produtividade na testemunha $\left(2.419 \mathrm{~kg} \mathrm{ha}^{-1}\right)$. $\left({ }^{2}\right)$ Fator de utilização do $\mathrm{N}: \mathrm{kg} \mathrm{ha}^{-1} \mathrm{de} \mathrm{N} / \mathrm{kg}$ ha ${ }^{-1} \mathrm{de}$ produtividade aumentada. $\left({ }^{3}\right)$ Para a época de aplicação de $\mathrm{N}$ no início do estádio $\mathrm{R}_{7}$, a produtividade com a dose de $90 \mathrm{~kg}$ ha ${ }^{-1}$ de $\mathrm{N}$ foi estimada pela equação contida na Figura 1.

O teor de proteína bruta nos grãos foi influenciado pela interação entre aplicação de $\mathrm{N}$ no estádio $\mathrm{V}_{4}$ e no início do $\mathrm{R}_{7}$. A aplicação de $\mathrm{N}$ no início do estádio $R_{7}$ proporcionou aumento linear no teor de proteína dos grãos, tanto sem, quanto com a aplicação de $90 \mathrm{~kg} \mathrm{ha}^{-1}$ de $\mathrm{N}$ no estádio $\mathrm{V}_{4}$ (Figura 2).
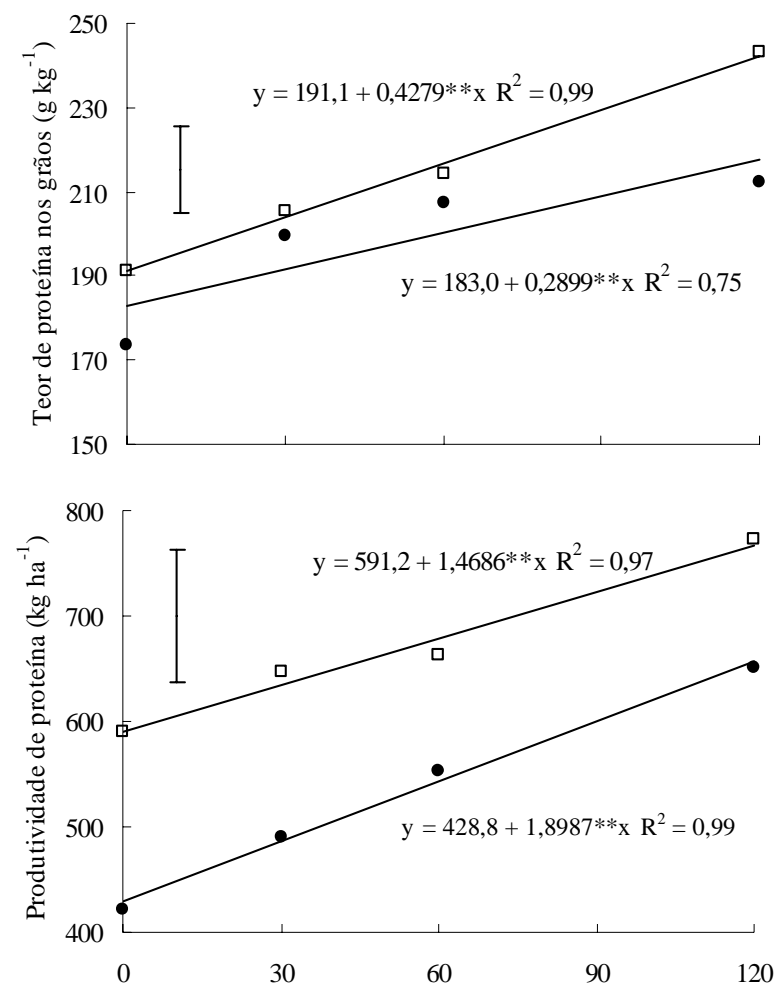

$\mathrm{N}$ em cobertura no início do estádio $\mathrm{R}_{7}\left(\mathrm{~kg} \mathrm{ha}^{-1}\right)$

Figura 2. Teor de proteína nos grãos e produtividade de proteína bruta pelo feijoeiro em sistema de plantio direto em função da aplicação de níveis de $\mathrm{N}$ em cobertura no início do estádio R7 (50 DAE), sem $(\bullet)$ e com ( $\square$ ) aplicação de $90 \mathrm{~kg} \mathrm{ha}^{-1}$ de $\mathrm{N}$ em cobertura no estádio V4 (22 DAE). ** Significativo a $1 \%$ de probabilidade pelo teste $t$. Barras verticais indicam o valor de DMS a 5\% de probabilidade.
No entanto, a combinação da aplicação de $\mathrm{N}$ no estádio $\mathrm{V}_{4}$, com aplicação no início do $\mathrm{R}_{7}$, promoveu a obtenção dos maiores teores de proteína nos grãos do feijoeiro cultivado em plantio direto. FARINELLI (2003) também obteve elevação do teor de proteína nos grãos do feijoeiro cv. Pérola, com aplicação de doses crescentes de $\mathrm{N}$ aplicadas em cobertura no estádio $\mathrm{V}_{4}$.

A elevação do teor de $\mathrm{N}$ nas folhas pode ter proporcionado o aumento do teor de proteína nos grãos, já que, no estádio de enchimento dos grãos, o N das folhas é translocado para eles (PORTES, 1996). Entretanto, pelos resultados, notou-se a possibilidade de se aumentar o teor de proteína nos grãos do feijoeiro mediante a aplicação de $\mathrm{N}$ no início do estádio de formação das vagens $\left(R_{7}\right)$. Segundo Rosolem (1987), apesar de haver translocação do $\mathrm{N}$ das folhas para as vagens, existe absorção do nutriente do solo nos estádios mais tardios da cultura, e o $\mathrm{N}$ absorvido nessa fase vai para os grãos, uma vez que os teores nas folhas diminuem no período correspondente.

A produção de proteína por área foi incrementada linearmente pela aplicação de $\mathrm{N}$ no início do estádio $R_{7}$, tanto sem, quanto com a aplicação de $90 \mathrm{~kg} \mathrm{ha}^{-1}$ de N no estádio $\mathrm{V}_{4}$ (Figura 2). Porém, foram obtidas maiores produções de proteína com a aplicação de $\mathrm{N}$ no estádio $\mathrm{V}_{4}$, devido às maiores produtividades de grãos, proporcionadas por esse tratamento (Figura 1). Bordin et al. (2003) também obtiveram aumento da produção de proteínas pelo feijoeiro cultivado em sistema de plantio direto sobre diferentes tipos de palhada.

\section{CONCLUSÕES}

1. Quando não é realizada adubação nitrogenada de cobertura no estádio $V_{4}$, a aplicação de $\mathrm{N}$ no início do estádio $\mathrm{R}_{7}$ aumenta a produtividade de grãos do feijoeiro, em sistema de plantio direto, sobre palhada de aveia-preta. 
2. A produtividade máxima de grãos é obtida com a aplicação exclusiva de $90 \mathrm{~kg} \mathrm{ha}^{-1}$ de $\mathrm{N}$ no estádio $\mathrm{V}_{4}$, sendo necessárias, para atingir o mesmo nível de produtividade, maiores doses de $\mathrm{N}$ quando aplicadas apenas em $R_{7}$. Quando é realizada aplicação de $\mathrm{N}$ em $\mathrm{V}_{4}$, adubações adicionais em $\mathrm{R}_{7}$ não proporcionam aumento de produtividade.

3. A aplicação de $\mathrm{N}$ em cobertura no estádio $\mathrm{V}_{4}$ é mais eficiente do que no $R_{7}$, acarretando maior incremento na produtividade do feijoeiro por unidade do nutriente aplicado.

4. A aplicação de $\mathrm{N}$ em cobertura, nos estádios $V_{4}$ e início do $R_{7}$, proporciona aumento no teor de proteína nos grãos do feijoeiro.

\section{REFERÊNCIAS}

AMBROSANO, E.J.; TANAKA, R.T.; MASCARENHAS, H.A.A.; RAIJ, B. van; QUAGGIO, J.A.; CANTARELA, H. Leguminosas e oleaginosas. In: RAIJ, B. van; CANTARELA, H.; QUAGGIO, J.A.; FURLANI, A.M.C. Recomendações de adubação e calagem para o Estado de São Paulo. 2.ed. Campinas: Instituto Agronômico e Fundação IAC, 1996. p.189-203. (Boletim Técnico, 100)

ANDRADE, M.J.B.; DINIZ, A.R.; CARVALHO, J.G.; LIMA, S.F. Resposta da cultura do feijoeiro à aplicação foliar de molibdênio e às adubações nitrogenadas de plantio e cobertura. Ciência e Agrotecnologia, Lavras, v.22, n.4, p.499508, 1998.

BORDIN, L.; FARINELLI, R.; PENARIOL, F.G.; FORNASIERI FILHO, D. Sucessão de cultivo de feijão-arroz com doses de adubação nitrogenada após adubação verde, em semeadura direta. Bragantia, Campinas, v.62, n.3, p.417-428, 2003.

CARVALHO, M.A.C.; ARF, O.;SÁ, M.E.; BUZETTI, S.; SANTOS, N.C.B.; BASSAN, D.A.Z. Produtividade e qualidade de sementes de feijoeiro (Phaseolus vulgaris L.) sob influência de parcelamentos e fontes de nitrogênio. Revista Brasileira de Ciência do Solo, Viçosa, v.25, n.4, p.617-624, 2001.

CERETTA, C.A.; BASSO, C.J.; HERBES, M.G.; POLETTO, N.; SILVEIRA, M.J. Produção e decomposição de fitomassa de plantas invernais de cobertura de solo e milho, sob diferentes manejos da adubação nitrogenada. Ciência Rural, Santa Maria, v.32, n. 1, p.49-54, 2002.

EMBRAPA. Centro Nacional de Pesquisa de Solos (Rio de Janeiro, RJ). Sistema Brasileiro de Classificação dos Solos. Rio de Janeiro: Embrapa-SPI/Embrapa-CNPS, 1999. 412 p.

FARINELLI, R. Resposta do feijoeiro (Phaseolus vulgaris L.) à adubação nitrogenada de cobertura em dois sistemas de manejo do solo. 2003. 75f. Dissertação (Mestrado em Agronomia) - Universidade Estadual Paulista-UNESP, . Botucatu.
FERNANDEZ, F.; GEPTS, P.; LOPES, M. Etapas de desarrollo de la planta de frijol (Phaseolus vulgaris L.). Cali: Centro Internacional de Agricultura Tropical, 1986. 34p.

GONÇALVES, C.N.; CERETTA, CA. Plantas de cobertura de solo antecedendo o milho e seu efeito sobre o carbono orgânico do solo, sob plantio direto. Revista Brasileira de Ciência do Solo, Viçosa, v.23, n.2, p.307-313, 1999.

HERNANI, L.C.; KURIHARA, C.H.; SILVA, W.M. Sistema de manejo do solo e perdas de nutrientes e matéria orgânica por erosão. Revista Brasileira de Ciência do Solo, Viçosa, v.23, n.1, p.145-154, 1999.

HUNGRIA, M.; NEVES, M.C.P.; VICTORIA, R.L. Assimilação do nitrogênio pelo feijoeiro. II. Absorção e translocação do N mineral e do $\mathrm{N}_{2}$ fixado. Revista Brasileira de Ciência do Solo, v.9, n.1, p.201-209, 1985.

MALAVOLTA, E.; VITTI, G.C.; OLIVEIRA, S.A. Avaliação do estado nutricional de plantas: princípios e aplicações. 2. ed. Piracicaba: Potafos, 1997. 319p.

MIYASAKA, S.; FREIRE, E.S.; MASCARENHAS, H.A.A. Modo e época de aplicação de nitrogênio na cultura do feijoeiro. Bragantia, Campinas, v.22, n.1, p.511-519, 1963.

OLIVEIRA, I.P.; ARAÚJO, R.S.; DUTRA, L.G. Nutrição mineral e fixação biológica de nitrogênio. In: ARAÚJO, R.S.; RAVA, C.A.; STONE, L.F.; ZIMMERMANN, M.J.O. (Coords.). Cultura do feijoeiro comum no Brasil. Piracicaba: Potafós, 1996. p.169221.

PIASKOWSKI, S.R.; RONZELLI JÚNIOR, P.; DAROS, E.; KOEHLER, H.S. Adubação nitrogenada em cobertura para o feijoeiro em plantio direto na palha. Scientia Agraria, Curitiba, v.2, n.1, p.67-72, 2001.

PORTES, T.A. Ecofisiologia. In: ARAÚJO, R.S.; RAVA, C.A.; STONE, L.F.; ZIMMERMANN, M.J.O. (Coords.). Cultura do feijoeiro comum no Brasil. Piracicaba: Potafós, 1996. p.101137.

RAIJ, B. van; QUAGGIO, J. A. Métodos de análise de solo para fins de fertilidade. Campinas: Instituto Agronômico, 1983. 31p. (Boletim Técnico, 81)

ROSOLEM, C.A. Calagem e adubação mineral. In: ARAÚJO, R.S.; RAVA, C.A.; STONE, L.F.; ZIMMERMANN, M.J.O. (Coords.). Cultura do feijoeiro comum no Brasil. Piracicaba: Potafós, 1996. p.353-390.

ROSOLEM, C.A. Nutrição e adubação do feijoeiro. Piracicaba: Potafos, 1987. 93p. (Boletim Técnico, 8)

SANTOS, A.B.; FAGERIA, N.K.; SILVA, O.F.; MELO, M.L.B. Resposta do feijoeiro ao manejo de nitrogênio em várzeas tropicais. Pesquisa Agropecuária Brasileira, Brasília, v.38, n.11, p.1265-1271, 2003.

SILVA, A.J.; RAMALHO, M.A.P.; GUEDES, G.A.A.; VALE, F.R. Resposta de cultivares de feijão (Phaseolus vulgaris L.) à adubação nitrogenada. I. Produção de grãos e seus componentes. Ciência e Prática, Lavras, v.13, n.2, p.348-355, 1989. 
SILVA, C.C.; SILVEIRA, P.M. Influência de sistemas agrícolas na resposta do feijoeiro (Phaseolus vulgaris L.) irrigado à adubação nitrogenada de cobertura. Pesquisa Agropecuária Tropical, Goiânia, v.30, n.1, p.86-96, 2000.

SILVA, G.M.; STONE, L.F.; MOREIRA, J.A.A. Manejo da adubação nitrogenada no feijoeiro irrigado sob plantio direto. Pesquisa Agropecuária Tropical, Goiânia, v.32, n.1, p.1-5, 2002.

SORATTO, R.P.; CARVALHO, M.A.C.; ARF, O. Teor de clorofila e produtividade do feijoeiro em razão da adubação nitrogenada. Pesquisa Agropecuária Brasileira, Brasília, v.39, n.9, p.895-901, 2004.
SORATTO, R.P.; SILVA, T.R.B.; ARF, O.; CARVALHO, M.A.C. Níveis e épocas de aplicação de nitrogênio em cobertura no feijoeiro irrigado em plantio direto. Cultura Agronômica, Ilha Solteira, v.10, n.1, p.89-99, 2001

STONE, L.F.; SILVEIRA, P.M. Efeitos de sistemas de preparo na compactação do solo, disponibilidade hídrica e comportamento do feijoeiro. Pesquisa Agropecuária Brasileira, Brasília, v.34, n.1, p.83-91, 1999.

WESTERMANN, D.T.; KLEINKOF, G.E.; PORTER, L.K.; LEGGERTT, G.E. Nitrogen sources for bean seed production. Agronomy Journal, Madison, v.73, p.660-664, 1981. 